\title{
High Energy Electron Transport in Solids
}

R. Snavely, Y. Aglitskii, K. U. Akli, F. Amiranoff, C. Andersen, D. Batani, S. D. Baton, T. Cowan, R. Town, R. R. Freeman, J. S. Green, H. Habara, T. Hall, S. P. Hatchett, D. S. Hey, J. M. Hill, J. Kaae, R. Kodama, M. H. Key, J. A. King, J. A. Koch, M. Koenig, K. Krushelnick, K. L. Lancaster, A.. J. MacKinnon, E. Martinolli, C. D. Murphy, M. Nakatsutsumi, P. Norreys, E. Perelli-Cippo, M. Rabec Lc Gloahec, B. Remington, C. Rousseaux, J. J. Santos, F. Scianitti, P. T. Simpson, C. Stoeckl, M. Tabak, K. A. Tanaka, W. Theobald, R. Town, T. Yabuuchi, B. Zhang, P. A. Norreys

\section{October 3, 2005}

\section{IFSA}

Biarritz, France

September 4, 2005 through September 9, 2005 
This document was prepared as an account of work sponsored by an agency of the United States Government. Neither the United States Government nor the University of California nor any of their employees, makes any warranty, express or implied, or assumes any legal liability or responsibility for the accuracy, completeness, or usefulness of any information, apparatus, product, or process disclosed, or represents that its use would not infringe privately owned rights. Reference herein to any specific commercial product, process, or service by trade name, trademark, manufacturer, or otherwise, does not necessarily constitute or imply its endorsement, recommendation, or favoring by the United States Government or the University of California. The views and opinions of authors expressed herein do not necessarily state or reflect those of the United States Government or the University of California, and shall not be used for advertising or product endorsement purposes. 


\section{High Energy Electron Transport in Solids}

\section{R.B. Stephens, General Atomics}

R.P.J. Snavely, Y. Aglitskii,K.U. Akli, F. Amiranoff, C. Andersen, D. Batani, S.D. Baton, T. Cowan, R. Town, R.R. Freeman, J.S. Green, H.

Habara, T. Hall, S.P. Hatchett, D.S. Hey, J.M. Hill, J. Kaae, R.

Kodama, M.H. Key, J.A. King, J.A. Koch, M. Koenig, K. Krushelnick,

K.L. Lancaster, A.J. MacKinnon, E. Martinolli, C.D. Murphy, M. Nakatsutsumi, P. Norreys, E. Perelli-Cippo, M. Rabec Le Gloahec, B. Remington, C. Rousseaux, J.J. Santos, F. Scianitti, P.T. Simpson, C. Stoeckl, M. Tabak, K.A. Tanaka, W. Theobald, R. Town, T. Yabuuchi, B. Zhang, and P.A. Norreys

Inertial Fusion Science and Applications Biarritz, France

IFT/P2005-082 4-9 Sept. 2005

This work was performed under the auspices of the U.S. Department of Energy by University of California, Lawrence Livermore National Laboratory under contract W-7405Eng-48. 


\section{Studying transport for fast ignition application}

1) Drive lasers compress the fuel

2) A Petawatt laser generates energetic (MeV) electrons

3) The electrons transport the ignition energy to the core

\section{Electrons}

\section{Fuel}

\section{Laser}

\section{or Protons}




\section{We use room temp metal to stand in for DT plasma}

- Cu-K $\mathrm{K}_{\alpha}$ fluorescence shows electron propagation

- A Bragg mirror images the fluorescence emission

- Observe propagation in slab and wire geometries

- Basic findings

- $\mathrm{e}^{-}$spread is independent of energy

- Energy deposition is proportional to energy

- Propagation length is approx the same in all

- Largest deposited energy requires corrections

- Temperature reduces mirror efficiency

-Resistance is limiting current

- Indications of surface bottleneck?

- Have developed new diagnostics to show local temperature, starting to give a handle on details. 


\section{We use $K_{\alpha}$ imaging to see electron transport in Al}
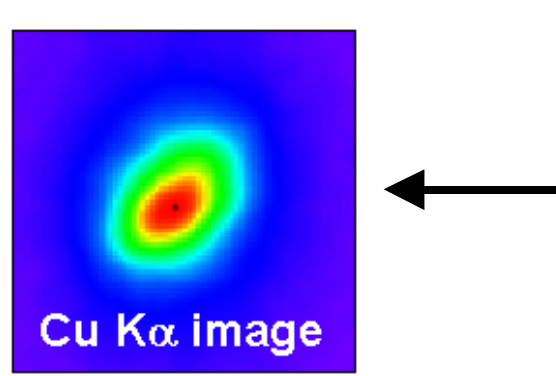

$C C D$

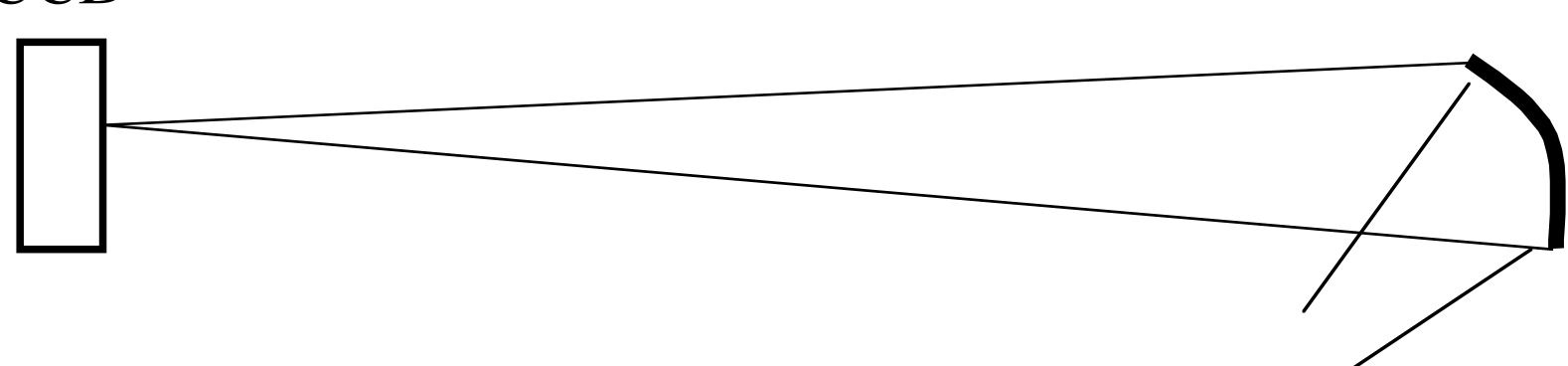

Bragg

Crystal

(Quartz 211)

- With Cu-K $\mathrm{K}_{\alpha}(8 \mathrm{keV})$ can see $~ 100 \mu \mathrm{m}$ into Al

- Use three geometries

- Buried layer: cross section of prop in Al/Cu/Al

- Alloy: Side view of prop thru Al:Cu

- Wire: transport confined to Cu wire

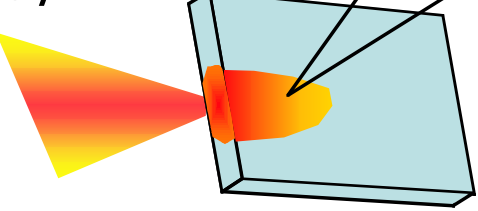




\section{Electron beam spread in Aluminum is independent of energy $(30 \mathrm{~J}, 70 \mathrm{~J}$, and $300 \mathrm{~J})$}

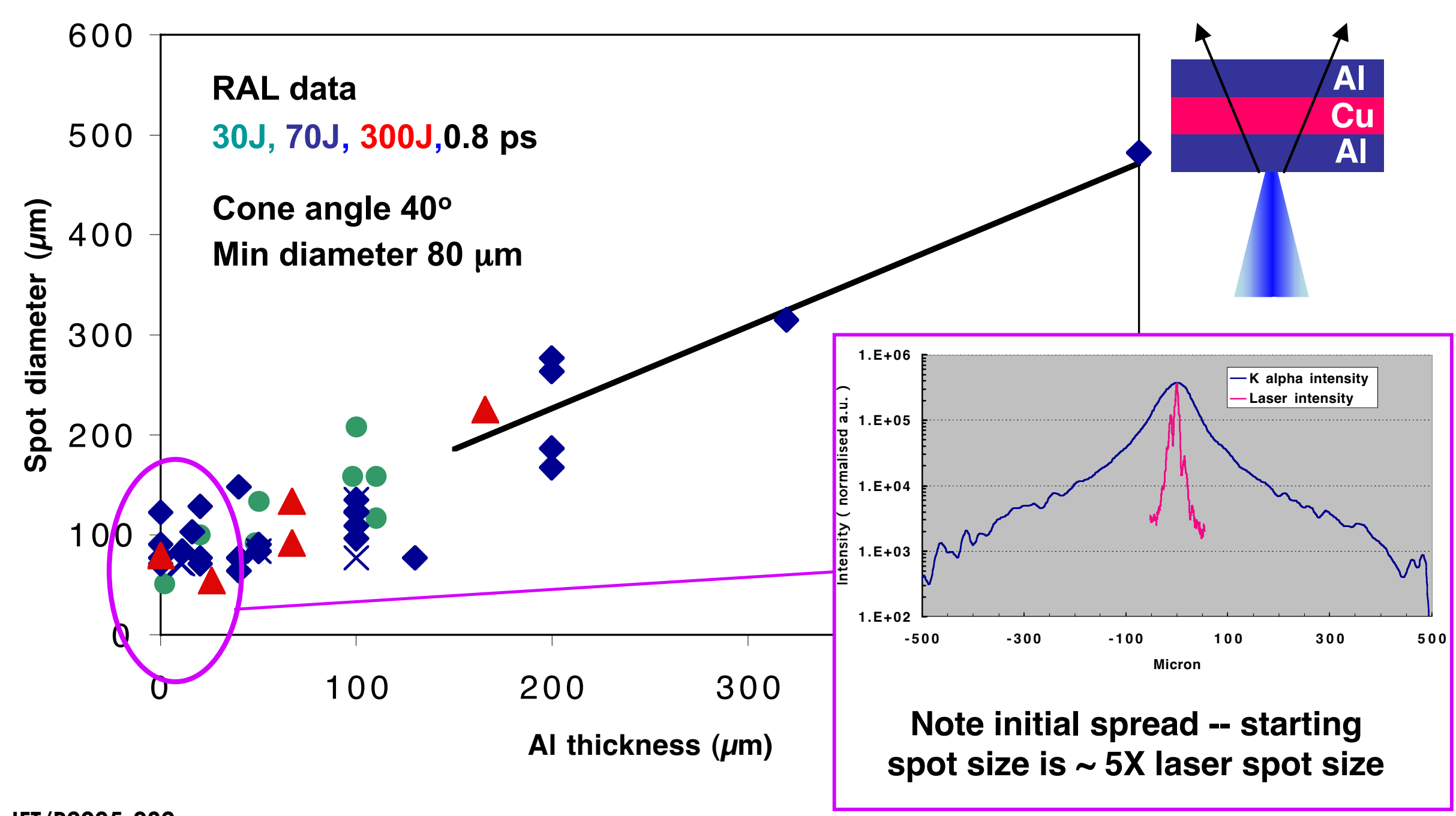

IFT/P2005-082

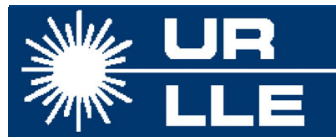

R Stephens et al. Phys Rev E,69, 066414 ( 2004)

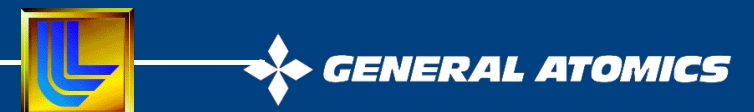




\section{Spread well described by heuristic Monte-Carlo model}
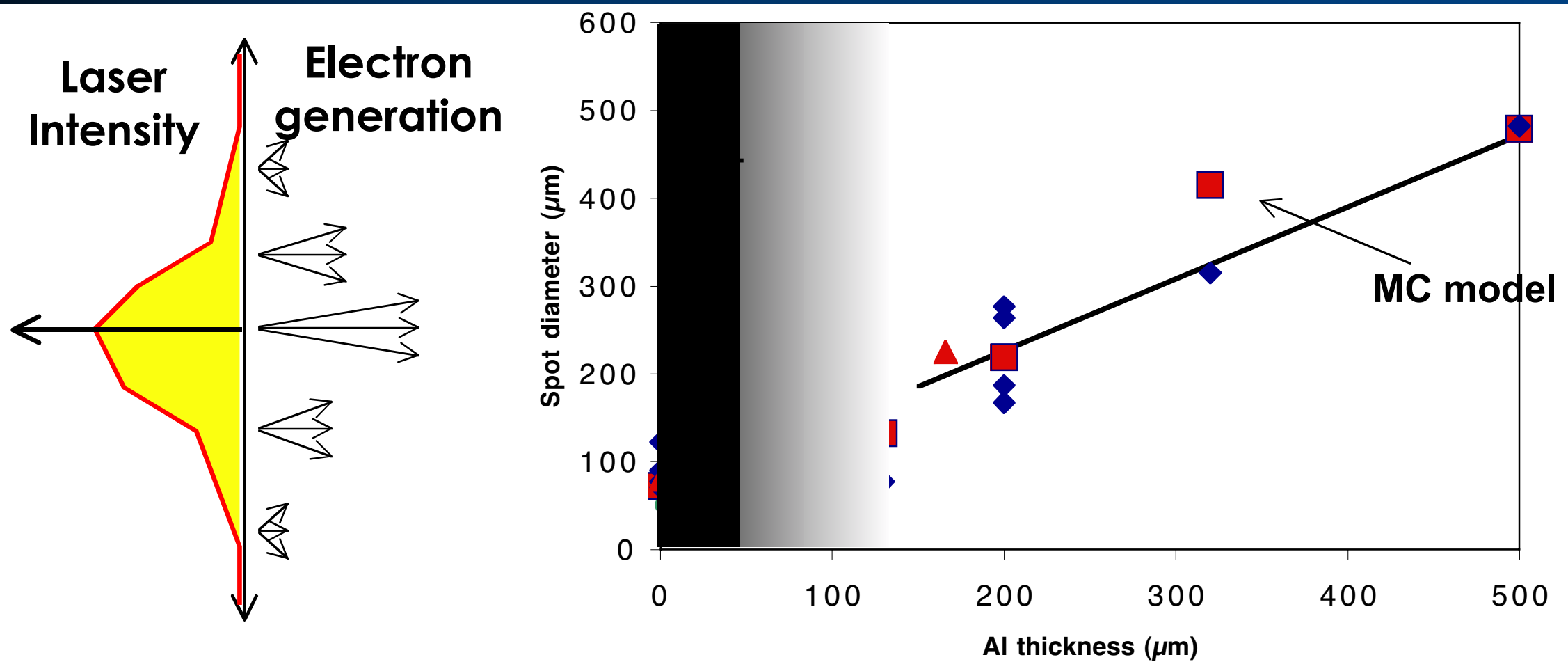

- $e^{-}$generation efficiency \& energy from local intensity (Beg scaling)

- Random transverse momentum independent of location

$\Rightarrow$ High energy e- are forward directed, low energy e- spread out 


\section{Fluorescence $\propto$ Laser energy and Cu fraction}

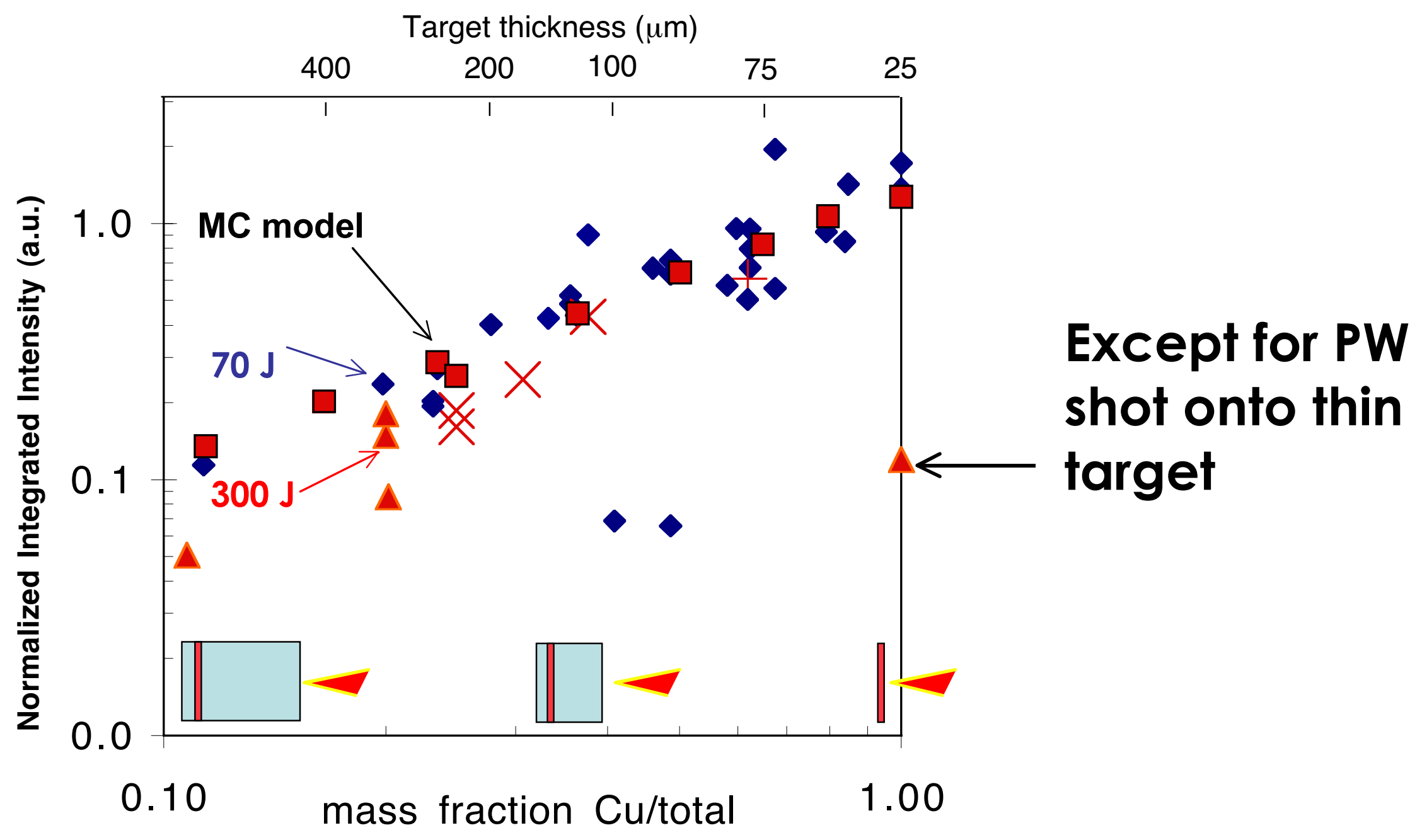

Fluorescence gets more complicated for high pulse energy

\begin{tabular}{|c|c|}
\hline N/1// UR & $\mathrm{OHIO}$ \\
\hline
\end{tabular}




\section{Propagation distance obtained from the peak $K_{\alpha}$ image brightness vs depth}

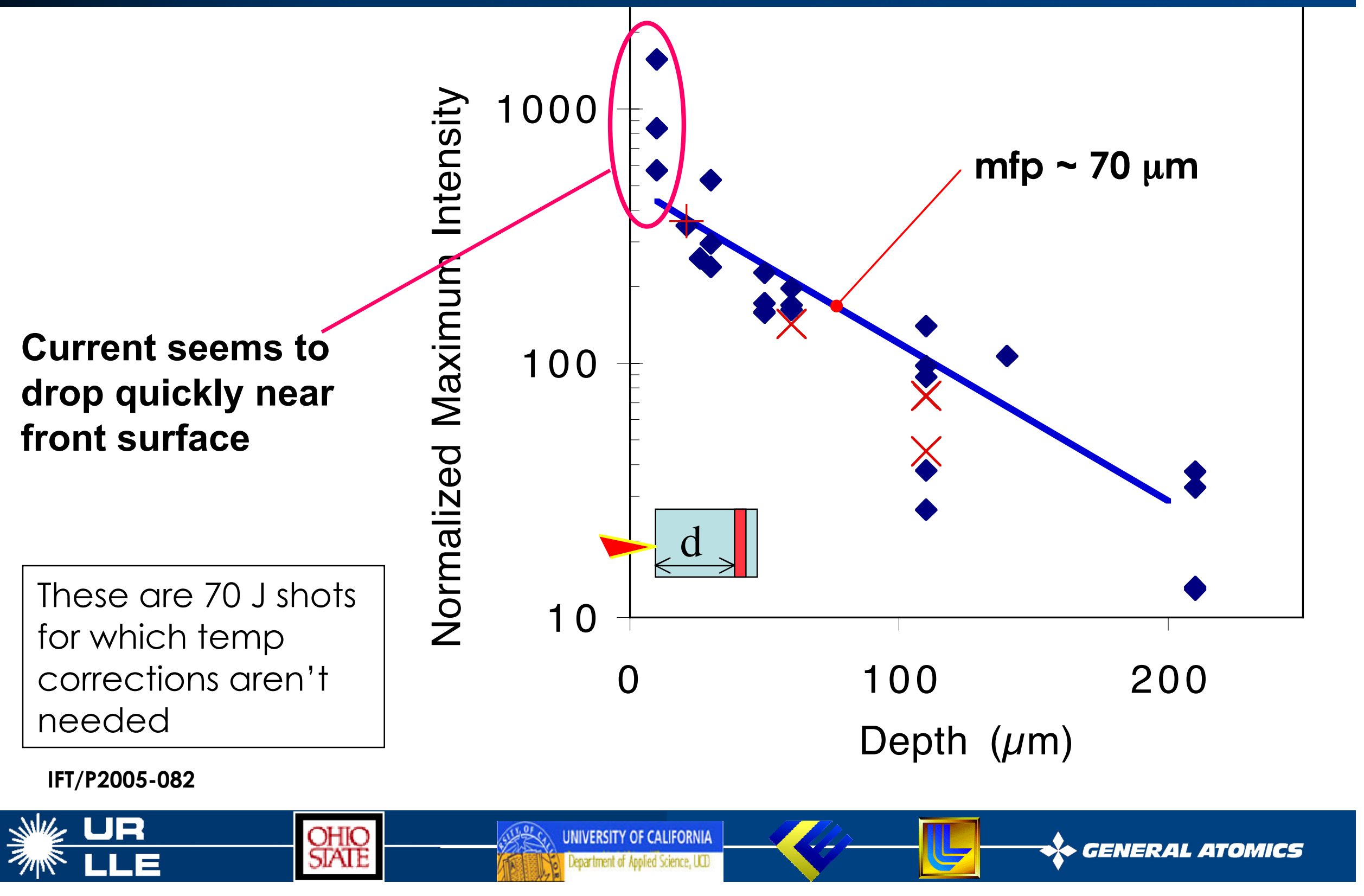




\section{Side view of CuAl gives the same result - spreading at entry surface and $\sim 70 \mu \mathrm{m}$ mfp}

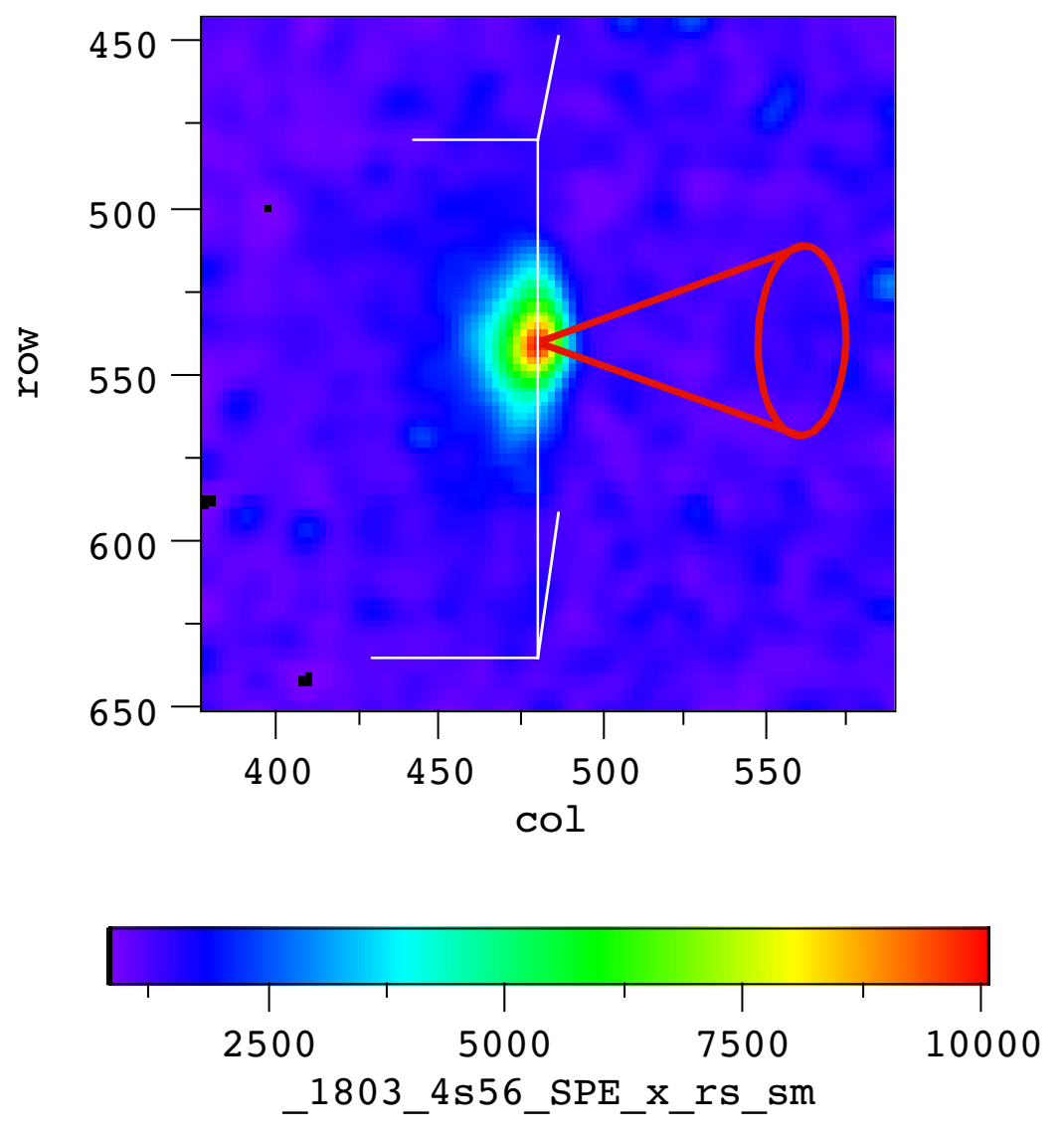

1/e decay length

$\sim 70 \mu \mathrm{m}$

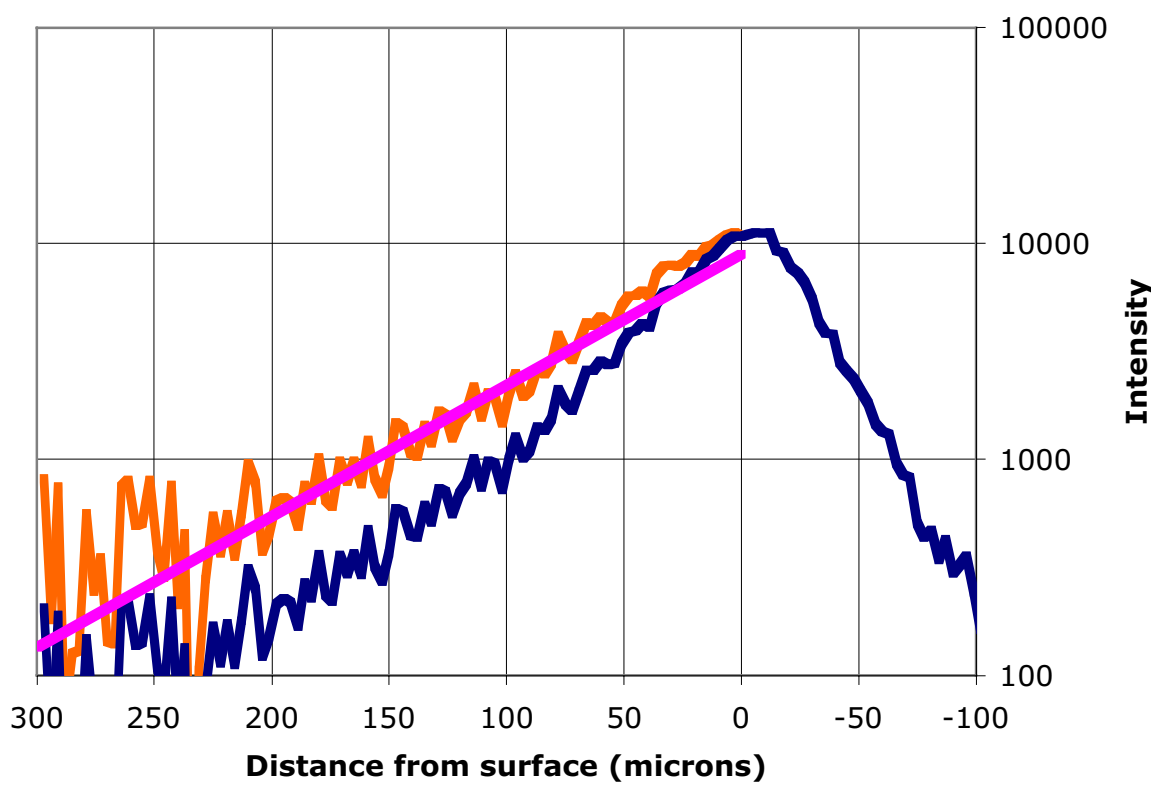

\section{IFT/P2005-082}




\section{And in Cu wires where the current can't spread}
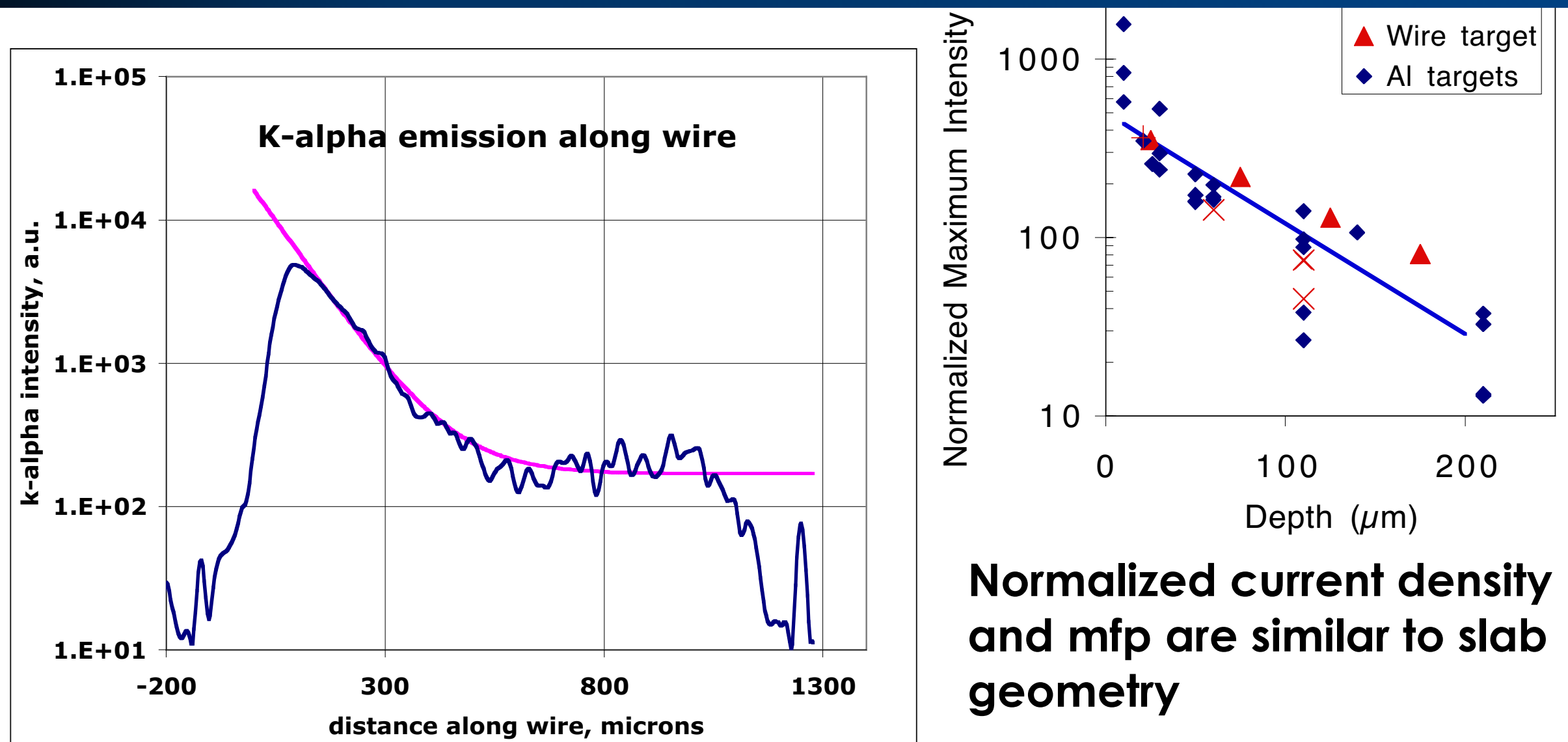

Normalized current density and $\mathrm{mfp}$ are similar to slab geometry

Cross section is much smaller, so total energy into wire is $\sim 2 \%$ of beam energy

IFT/P2005 


\section{With increasing current we are getting into complications}

- Reached current densities that require more sophisticated diagnostic

- Must account for temperature

- Resistance limitations become important

- Challenge is in understanding the laser-plasma interface region 


\section{Have added HOPG spectrometers for better understanding of temperature gradients}

256 eV XUV image

- $0.5 \mu \mathrm{m} \mathrm{Al} / 5 \mu \mathrm{m} \mathrm{Cu}$ target

- $500 \mu \mathrm{m} \times 500 \mu \mathrm{m}$ size

- $0.5 \mathrm{ps}, 300 \mathrm{~J}$ irradiation

Peak temp 2x general temp $\rightarrow$ strong heating from initial beam

3:1 front:back intensity ratio in $\mathrm{He}_{\alpha}$ $\rightarrow$ strong axial temp gradient

$\rightarrow$ front surface $\sim 2 \mathrm{keV}$

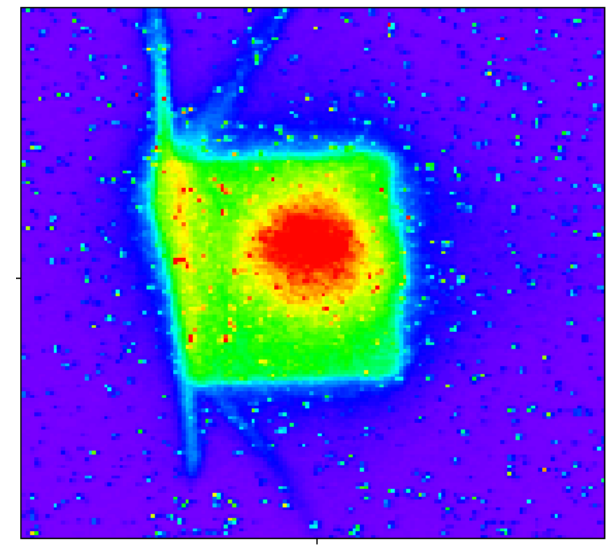

Cu K shell spectrum
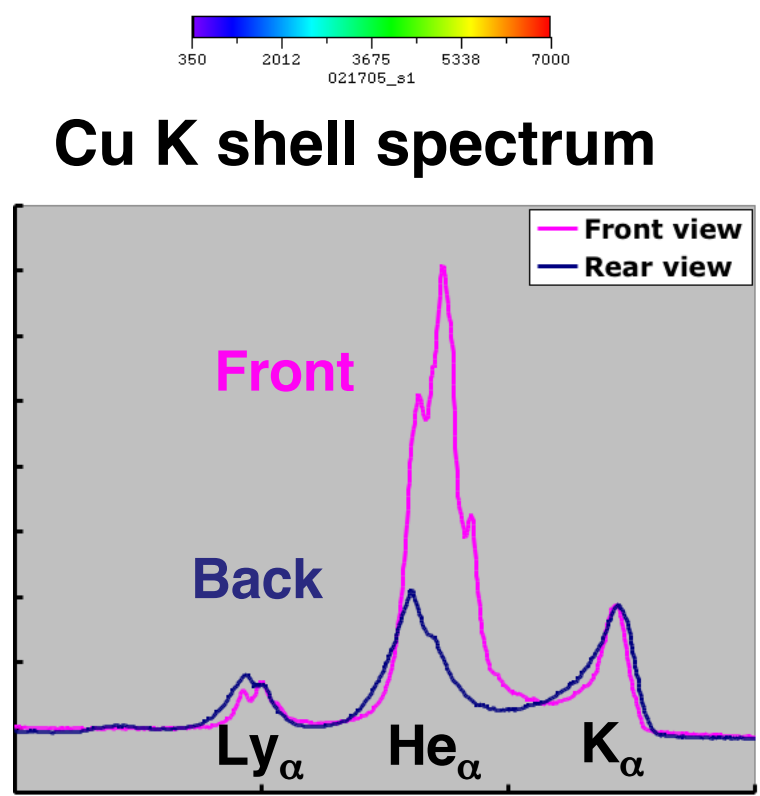


\section{Fluorescence collection efficiency decreases with temperature}
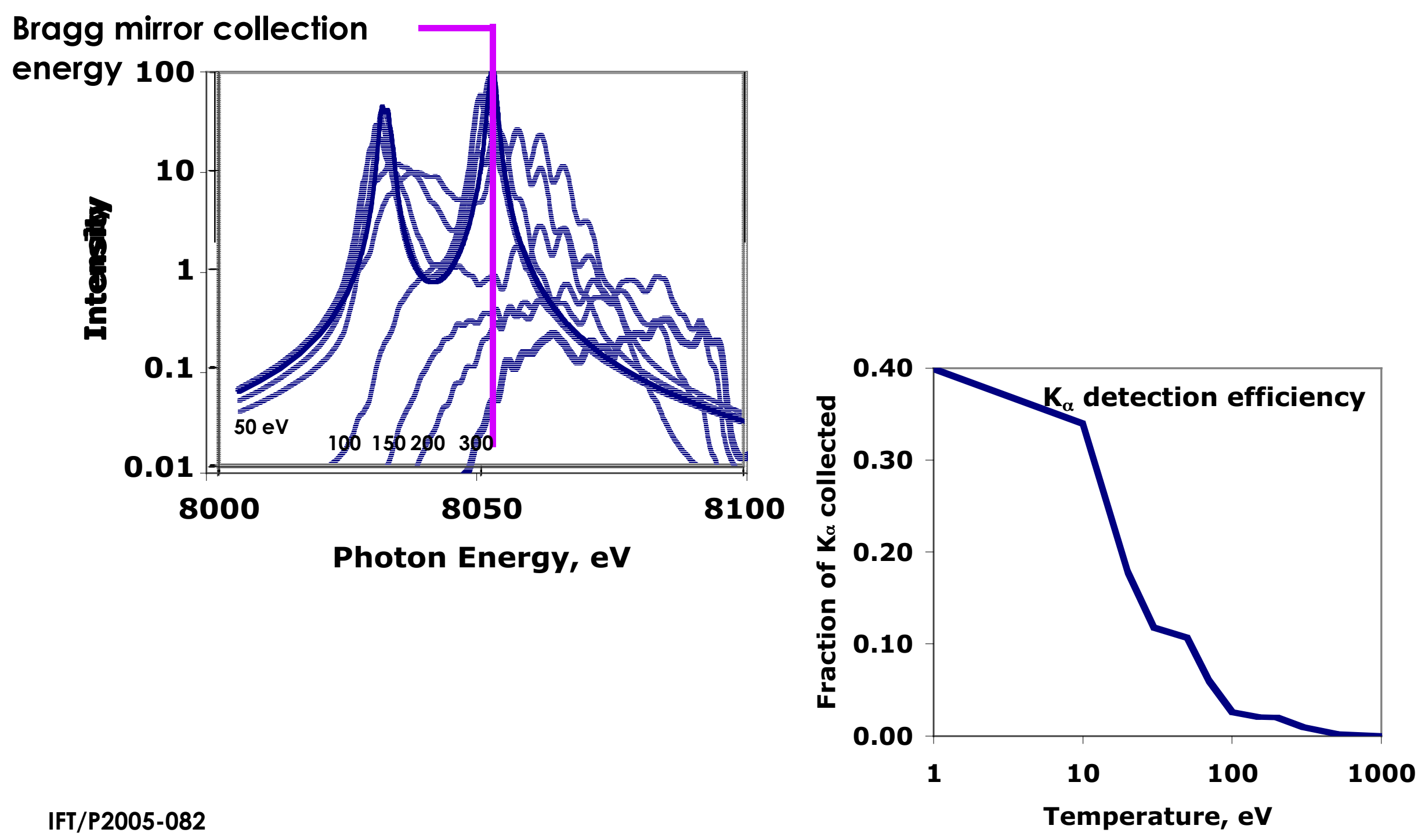

IFT/P2005-082

SIAIE




\section{Resistivity limits propagation at high current density}

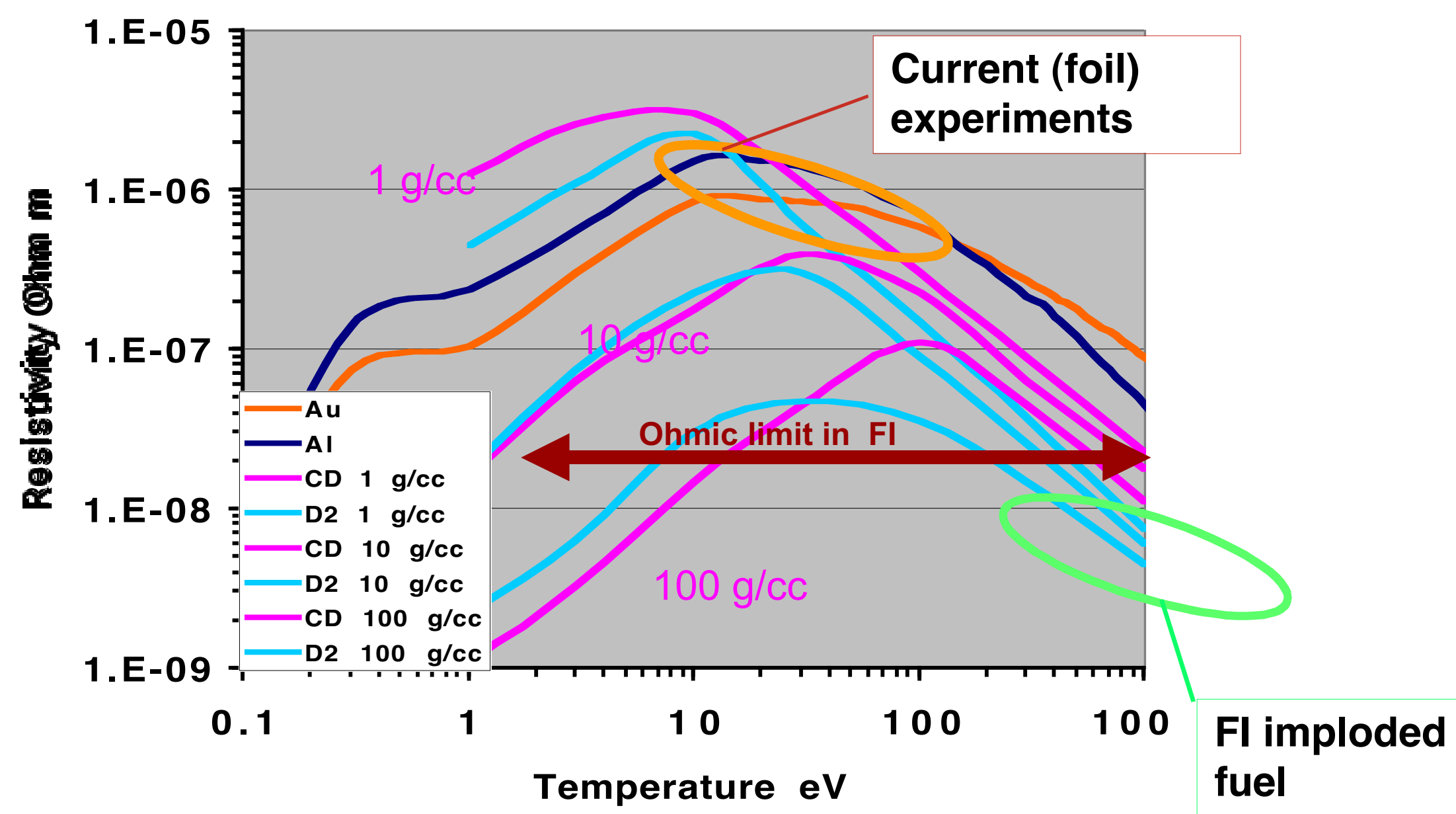

IFT/P2005-082 


\section{Higher current would cause stronger limitations.}
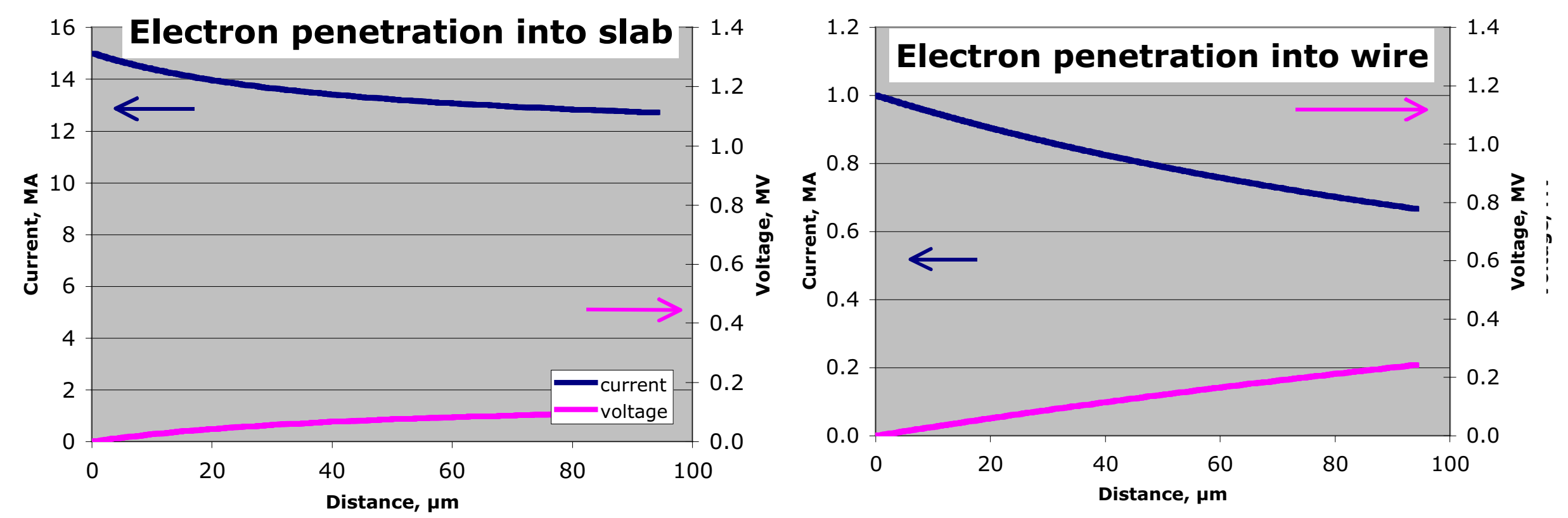

Current into the wire was limited so fields aren't too bad

IFT/P2005-082

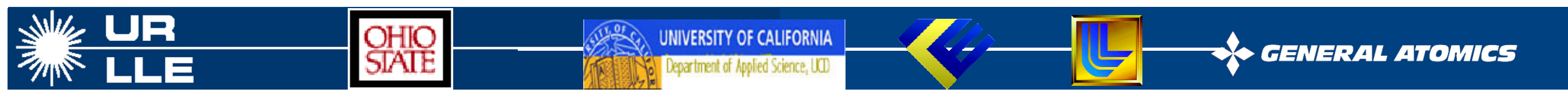




\section{Summary}

- Currents are still scaling with increasing intensity

- Propagation lengths are appropriate - $100 \mu \mathrm{m}$

- Reached current densities that require more sophisticated diagnostic

- HOPG spectrometers for current and temperature

- Resitivity may be limiting wire current

- Challenge is in understanding the laser-plasma interface region

- Created diagnostics and analyses to probe that area

- Adding packages to LSP for self-consistent electron creation in plasma 